\title{
In situ measurement of state transition in cyanobacterial blooms: kinetics and extent of the state change in relation to underwater light and vertical mixing
}

\author{
Hendrik Schubert, Rodney M. Forster*, Sigrid Sagert \\ Department of Ecology, Faculty of Biology, University of Rostock, Freiligrathstrasse 7/8, D-18055 Rostock, Germany
}

\begin{abstract}
Measurements of spectral scalar irradiance were made in a shallow estuarine system during a phytoplankton bloom in summer 1994. High concentrations of dissolved organic matter (DOM) and pigments resulted in strong attenuation of light within the upper $1 \mathrm{~m}$ of the water column. Spectral analysis showed an increase in the ratio of far-red (>700 nm) irradiance to total photosynthetically available radiation (PAR) as depth increased. Under these conditions it is expected that state transition may occur, as far-red light is preferentially absorbed by Photosystem 1 (PS1). Measurements of fluorescence emission at $77 \mathrm{~K}$ from natural phytoplankton samples as well as from laboratory-grown unialgal cultures showed that redistribution of excitation energy between the photosystems occurred in response to changes in the spectral light environment. Exposure to the far-red-enriched lower euphotic zone induced State 1 (whereby more light energy was directed towards Photosystem 2, PS2), whereas algae reverted to State 2 (redirection of light energy away from PS2) at the surface or after exposure to near-dark conditions at the bottom of the euphotic zone. Differences in the kinetics of state transition between green algae and cyanobacteria together with estimation of the wind-induced mixing time of the water column are discussed with respect to photoacclimation. For both natural phytoplankton and laboratory cultures, state transition occurred on a time scale equal to or faster than the time required for 1 vertical mixing cycle. The faster response of cyanobacteria to changes in spectral irradiance in the water column may be an important factor contributing to cyanobacterial dominance in hypertrophic waters under light-limited conditions
\end{abstract}

KEY WORDS: Algal blooms - Cyanobacteria - State transition Photosynthesis - Vertical mixing Underwater light - Acclimation - Light-harvesting pigments - Low temperature fluorescence emission

\section{INTRODUCTION}

Efficient oxygenic photosynthesis requires the cooperation of 2 photosystems (PS1 and PS2) to produce linear electron transport across the photosynthetic membrane from the electron donor, $\mathrm{H}_{2} \mathrm{O}$, to an acceptor, usually $\mathrm{CO}_{2}$. Optimal efficiency of photosynthesis is only achieved when there is a balanced input of light energy to both photosystems. Due to differences in the absorption spectra of the light-harvesting pigment complexes serving the photosystems, imbalances in

•E-mail: rod.forster@biologie.uni-rostock.de the input of excitation energy to each photosystem may occur under certain irradiance conditions, particularly in the aquatic environment. Photoautotrophs have evolved various strategies to equilibrate energy distribution in response to changes in incident irradiance. In the long run this can be achieved by alteration of the numbers of PS1 and PS2 reaction centres or their associated antenna systems (Fujita et al. 1985, Falkowski \& LaRoche 1991). A short-term acclimation to changing spectral distribution of light, denoted state transition, was simultaneously described for the unicellular red alga Porphyridium cruentum by Murata (1969) and for the green alga Chlorella pyrenoidosa by Bonaventura \& Myers (1969). It was observed that 
exposure to light selectively irradiating PS2 resulted in a substantial redirection of captured light energy from PS2 to PS1 (transition from State 1 to State 2), with the reverse occurring after exposure to light predominantly absorbed by PS1.

By means of this regulatory mechanism the rate of excitation energy delivered to each reaction centre can be equilibrated, a high rate of photochemistry is maintained (Veeranjaneyulu \& Leblanc 1994), and the supply of ATP and NADPH generated is balanced to the requirements of the Calvin cycle reactions (Horton 1989). State transition responses were subsequently discovered in many other groups of algae and higher plants (reviewed by Fork \& Satoh 1986 , Williams \& Allen 1987, Biggins \& Bruce 1989). The mechanism of state transition in green algae and higher plants is thought to involve reversible phosphorylation of the main light-harvesting pigment protein LHC (Horton et al. 1981, Canaani et al. 1984). Electrostatic repulsion due to a more negative surface charge density after phosphorylation causes uncoupling of LHC and the PS2 reaction centre (Allen 1992). A similar mechanism has been proposed for the phycobilisome (PBS) antenna of cyanobacteria and red algae (Mullineaux 1992) but has not yet been accepted due to conflicting experimental evidence (e.g. Bruce et al. 1985). An alternative hypothesis states that distribution of excitation energy is regulated by the degree of energy transfer from the reaction centre of PS2 to that of PS1 (termed the spillover mechanism), rather than by changes in the optical cross-section of the photosystems (Biggins \& Bruce 1989).

It has been suggested that the major role of state transition in algal physiology concerns the ability of algae to alternate between cyclic and noncyclic photophosphorylation, and hence alter the supply of ATP relative to reductant (Wollman \& Bulté 1989). This fast metabolic adjustment can have important ecological relevance when cells encounter transient pools of nutrients which differ in the degree of reduction required after uptake (Mohanty et al. 1991).

State transition caused by changes in irradiance is not thought to have a significant role for phytoplankton in most oceanic and coastal waters (Falkowski et al. 1994), as irradiance conditions which induce State 1 do not occur. However, the irradiance conditions in dense phytoplankton blooms can be very different from the normal situation in coastal waters. The aim of this work was to characterise the underwater light regime within a plankton bloom and to record changes in the energy distribution between the photosystems which occur at different depths in the water column. We demonstrate here the existence of light-driven state transitions under natural irradiance conditions.

\section{MATERIALS AND METHODS}

Location of measurements. Measurements of the underwater light climate and parallel monitoring of phytoplankton fluorescence parameters were made on 2 separate days in June 1994 at a station situated by a long, shallow coastal inlet of the Baltic Sea (Zingst, Mecklenburg-West Pomerania, Germany; $54^{\circ} 55^{\prime} \mathrm{N}$,

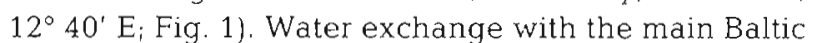
Sea from this highly productive, estuarine system is restricted due to lack of tidal exchange, and only occurs after prolonged periods of strong wind. The enclosed area is classified as eutrophic in the outer parts and hypertrophic in the inner parts furthest from the open sea, with a high nutrient loading due to runoff from agricultural land. Phytoplankton blooms are a permanent feature of the system, with chlorophyll a (chl a) concentrations frequently reaching $100 \mathrm{mg} \mathrm{m}^{-3}$ At the time of these measurements the phytoplankton community was dominated by cyanobacteria. The colonial species Aphanothecae sp. was numerically most abundant. Green algae were also present in the bloom, but at much lower population densities than the cyanobacteria.

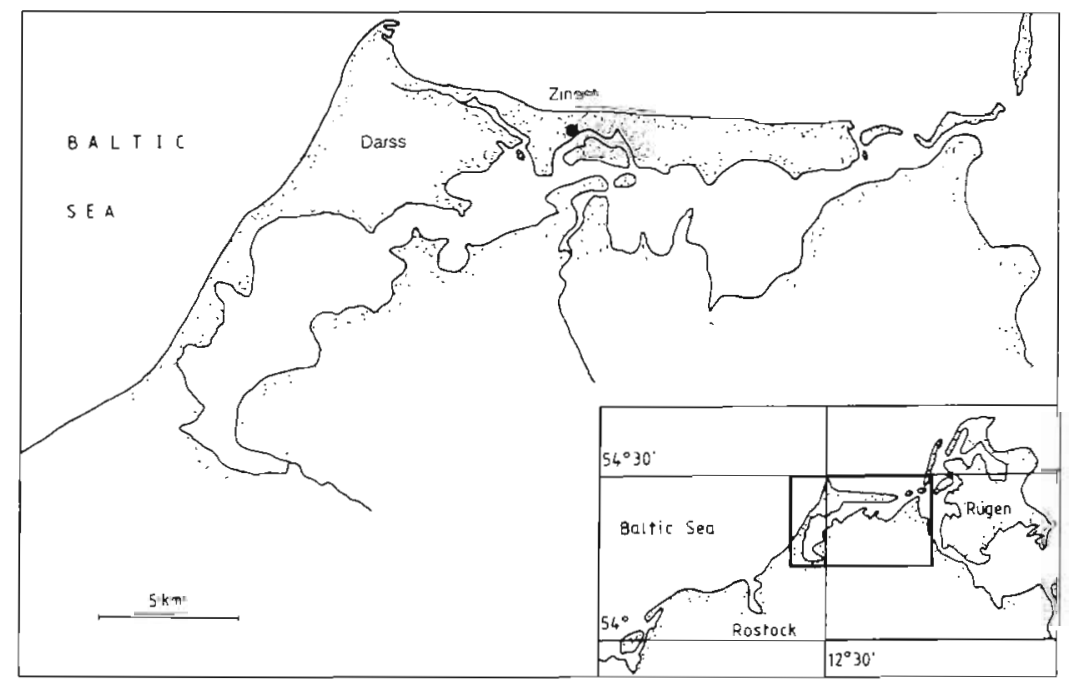

Fig. 1 Map of the investigation area (main map) showing the Darss-Zingst estuary system, with measuring station at Zingst, and (inset) the surrounding north German coastline 
Light measurements. Scalar irradiance both at the surface and underwater was measured with a highresolution spectroradiometer (Macam Photometrics Ltd, Livingston, Scotland, model SR-9910), equipped with a $10 \mathrm{~m}$ quartz light guide ending in a spherical light collector. Further details of underwater light measurement using this equipment are given in $R$. $M$. Forster \& H. Schubert (unpubl.). Successive scans at intervals between 20 and $150 \mathrm{~cm}$ were used to calculate the diffuse attenuation coefficient (Smith 1968). All irradiance measurements are presented in quantametric units; underwater measurements are immersion-effect corrected.

Sample preparation and treatments. Unialgal cultures of a cyanobacterium (Synechocystis sp. PCC6803) and 2 species of green alga (Chlorella vulgaris, University of Göttingen Culture Collection; Scenedesmus quadricauda) were used for comparison with the responses of the mixed natural phytoplankton. Algae were precultured in BG-11 medium (Rippka et al. 1979) with constant aeration and an irradiance of $40 \mu \mathrm{mol} \mathrm{m}^{-2} \mathrm{~s}^{-1}$.

Natural phytoplankton were collected from different depths within the bloom by means of a dark bottle which closed automatically at preset depths. Samples of cells were quickly retrieved from the bottle, injected with a syringe into glass capillaries, and either frozen immediately in liquid nitrogen (whole process complete in $<15 \mathrm{~s}$ ) or exposed to different light treatments for short periods before freezing.

A far-red (FR) light-emitting diode (Walz 102-FR) was used to preferentially excite PS1 of samples. A $150 \mathrm{~W}$ tungsten lamp with a $475 \mathrm{~nm}$ interference filter was used to define PS2 irradiance for green algae [absorbed by chlorophyll $b$ (chl $b$ ) of LHC]. For cyanobacteria, a $620 \mathrm{~nm}$ interference filter was used to produce PS2 light (absorbed by phycocyanin, PC).

Low-temperature emission spectra. The distribution of excitation energy between PS1 and PS2 can be estimated (Butler 1978) by measuring the fluorescence emission from each photosystem at low temperature (PS1 is non-fluorescent at room temperature in these species).

Frozen glass capillaries containing algae were scanned in the low temperature accessory of a spectrofluorimeter (Hitachi Inc., Kyoto, Japan, model F4010), with excitation wavelengths set to either $440 \mathrm{~nm}$ for chl $a, 475 \mathrm{~nm}$ for chl $b$ of green algae, or $620 \mathrm{~nm}$ for PC of cyanobacteria. The red-sensitive photomultiplier was protected from scattered excitation light by a Schott RG-620 cut-off filter. Emission of the cells was measured at $1 \mathrm{~nm}$ intervals from 640 to $750 \mathrm{~nm}$. Ratios of PS1 emission to PS2 emission were determined from the peak heights at 730 and $685 \mathrm{~nm}$ respectively (see Fig. 5). Data presented are means \pm standard deviations (SD) of 3 different samples.

\section{RESULTS}

Total scalar irradiance decreased rapidly with depth on both days, resulting in a mean euphatic zone depth of $1.1 \mathrm{~m}$ from 13 to 15 June 1994 and $0.6 \mathrm{~m}$ on 23 June 1994. There were large changes in the spectral distribution of light within the phytoplankton bloom. The presence of high concentrations of dissolved organic matter (DOM) was responsible for attenuation of virtually all ultraviolet and blue light within the first $20 \mathrm{~cm}$ (Fig. 2, Table 1). The effects of absorption by the cyanobacterial pigment PC $(620 \mathrm{~nm})$, and by the redband of chlorophyll $(675 \mathrm{~nm})$ were clearly visible in the underwater light distribution (Fig. 2) and in the spec-

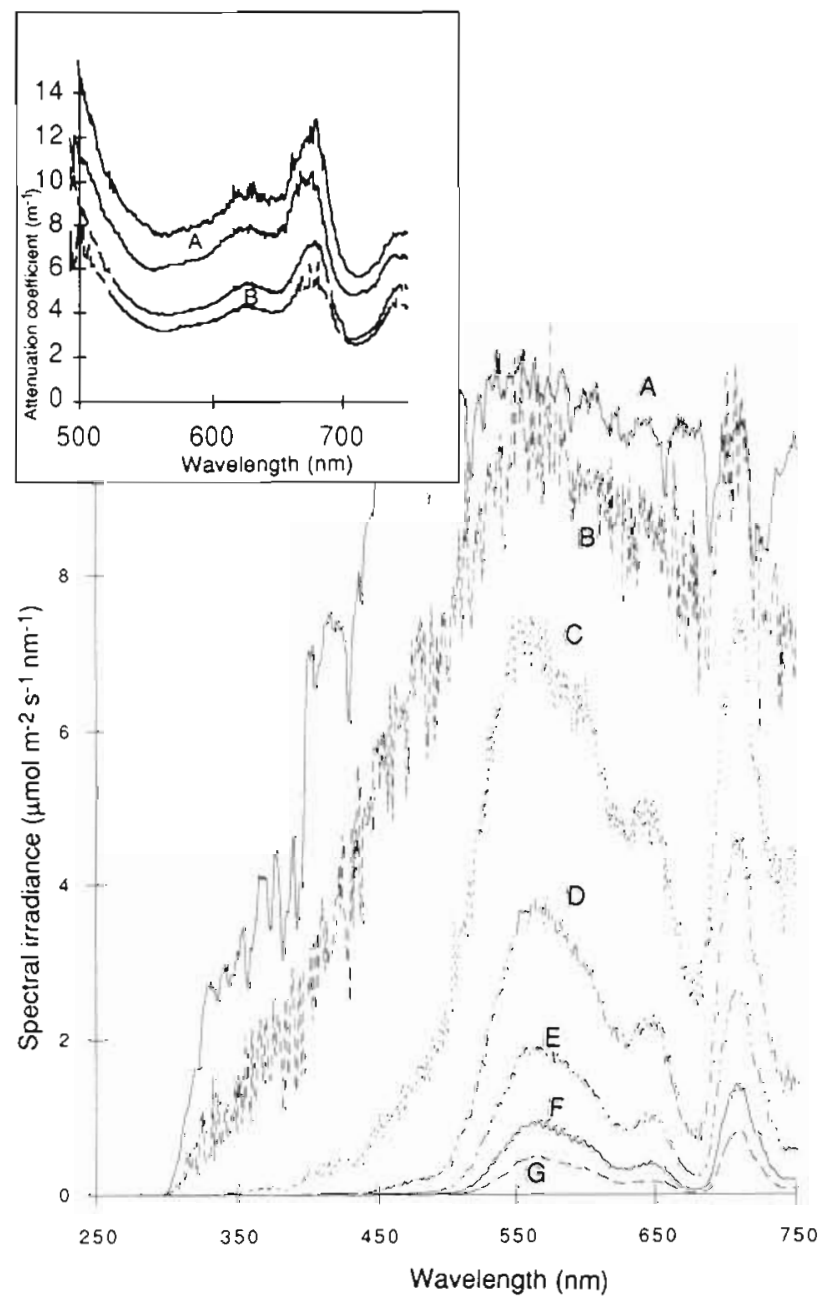

Fig. 2. Main diagram: spectral irradiance distribution in the Darss-Zingst estuary at $13: 20 \mathrm{~h}$ on 14 June 1994 . From top curve to bottom: (A) scalar irradiance at surface, (B) $1 \mathrm{~cm}$, (C) $20 \mathrm{~cm}$, (D) $40 \mathrm{~cm}$, (E) $60 \mathrm{~cm}$, (F) $80 \mathrm{~cm}$ and (G) $100 \mathrm{~cm}$ depth. Inset: attenuation coefficients were calculated at each wavelength from plots of $\log _{e}$ irradiance versus depth $(\mathrm{m})$. The range of attenuation coefficients ( $1 \mathrm{SD}$ above and below the mean) recorded on each day is plotted. (A) Upper pair of curves: 23 June 1994; (B) lower pair of curves: 13 to 16 June 1994 
Table 1 Variation of photon distribution in the wavelength bands: blue (400 to $500 \mathrm{~nm}$ ), green (500 to $600 \mathrm{~nm})$, red (600 to $700 \mathrm{~nm}$ ) or far-red (700 to $750 \mathrm{~nm}$ ) at different times and water column depths. Values in parentheses indicate percentage of total irradiance. Depth of euphotic zone is predicted as that at which PAR irradiance is reduced to $1 \%$ of that immediately below the surface (Kirk 1994). Solar elevation was calculated by direct measurement at each time point. Mean Secchi disc depths were $0.2 \mathrm{~m}$ for 14 June 1994 and $0.15 \mathrm{~m}$ for 23 June 1994

\begin{tabular}{|c|c|c|c|c|c|c|c|c|}
\hline \multirow{2}{*}{$\begin{array}{l}\text { Time, solar } \\
\text { elevation }\end{array}$} & \multirow[t]{2}{*}{ Depth $(\mathrm{cm})$} & \multicolumn{4}{|c|}{ Scalar irradiance $\left(\mu \mathrm{mol} \mathrm{m} \mathrm{m}^{-2} \mathrm{~s}^{-1}\right)$} & \multicolumn{3}{|c|}{$1 \%$ depth $(\mathrm{m})$} \\
\hline & & Blue & Green & Red & Far-red & $565 \mathrm{nr}$ & & PAR \\
\hline \multicolumn{9}{|l|}{14 June 1994} \\
\hline \multirow[t]{4}{*}{$07: 15 \mathrm{~h}, 16.7^{\circ}$} & 0 & $112.28(27)$ & $125.85(30)$ & $119.24(28)$ & $62.03(15)$ & 1.4 & 1.7 & 1.2 \\
\hline & 20 & $7.02(7)$ & $41.70(39)$ & $35.34(33)$ & $22.35(21)$ & & & \\
\hline & 80 & $0.03(0)$ & $3.04(42)$ & $1.98(27)$ & $2.21(30)$ & & & \\
\hline & 150 & $0.02(2)$ & $0.44(38)$ & $0.25(21)$ & $0.45(39)$ & & & \\
\hline \multirow[t]{4}{*}{$09: 10 \mathrm{~h}, 33.5^{\circ}$} & 0 & $169.23(24)$ & $213.61(30)$ & $216.04(30)$ & $115.60(16)$ & 1.3 & 1.5 & 1.1 \\
\hline & 20 & $12.95(7)$ & $78.42(40)$ & $62.90(32)$ & $39.95(21)$ & & & \\
\hline & 80 & $0.04(0)$ & $9.22(50)$ & $4.22(23)$ & $5.06(27)$ & & & \\
\hline & 150 & $0.00(0)$ & $0.45(42)$ & $0.20(18)$ & $0.42(40)$ & & & \\
\hline \multirow[t]{4}{*}{$11: 08 h, 49.5^{\circ}$} & 0 & $446.61(26)$ & $514.00(30)$ & $506.20(29)$ & $266.42(15)$ & 1.3 & 1.8 & 1.1 \\
\hline & 20 & $32.60(7)$ & $193.00(41)$ & $154.52(33)$ & $92.18(20)$ & & & \\
\hline & 80 & $0.06(0)$ & $42.96(52)$ & $26.46(32)$ & $13.33(16)$ & & & \\
\hline & 150 & $0.00(0)$ & $1.51(24)$ & $0.76(12)$ & $4.05(64)$ & & & \\
\hline \multirow[t]{4}{*}{$13: 20$ h, $58.8^{\circ}$} & 0 & $871.42(26)$ & $1040.36(31)$ & $988.08(29)$ & $472.38(14)$ & 1.4 & 1.6 & 1.1 \\
\hline & 20 & $94.55(7)$ & $589.88(42)$ & $456.78(32)$ & $276.28(19)$ & & & \\
\hline & 80 & $0.24(0)$ & $55.79(44)$ & $33.54(27)$ & $36.68(29)$ & & & \\
\hline & 100 & $0.08(0)$ & $27.11(43)$ & $15.47(25)$ & $19.96(32)$ & & & \\
\hline \multirow[t]{4}{*}{$16: 40 \mathrm{~h}, 43.0^{\circ}$} & 0 & $633.90(29)$ & $790.07(36)$ & $508.60(23)$ & $246.87(11)$ & 1.2 & 1.8 & 1.0 \\
\hline & 20 & $40.12(8)$ & $207.46(44)$ & $142.16(30)$ & $83.65(18)$ & & & \\
\hline & 80 & $0.04(0)$ & 23.08 & $19.70(28)$ & $28.72(40)$ & & & \\
\hline & 150 & $0.00(0)$ & $0.71(22\}$ & $0.41(13)$ & $2.09(65)$ & & & \\
\hline \multicolumn{9}{|l|}{23 June 1994} \\
\hline \multirow[t]{4}{*}{$08: 30 \mathrm{~h}, 275^{\circ}$} & 0 & $230.19(24)$ & $281.16(30)$ & $289.43(31)$ & $147.09(16)$ & 0.6 & 0.8 & 0.6 \\
\hline & 20 & $1.82(3)$ & $24.27(35)$ & $23.09(34)$ & $19.21(28)$ & & & \\
\hline & 80 & $0.00(0)$ & $0.15(16)$ & $0.15(16)$ & $0.65(69)$ & & & \\
\hline & 100 & $0.00(0)$ & $0.12(28)$ & $0.06(15)$ & $0.24(58)$ & & & \\
\hline \multirow[t]{4}{*}{$12: 45 \mathrm{~h}, 57.8^{\circ}$} & 0 & $669.82(25)$ & $811.41(30)$ & $795.49(30)$ & $397.73(15)$ & 0.6 & 0.8 & 0.5 \\
\hline & 30 & $3.92(1)$ & $128.75(38)$ & $92.83(28)$ & $109.34(33)$ & & & \\
\hline & 80 & $0.00(0)$ & $1.91(31)$ & $0.84(14)$ & $3.40(55)$ & & & \\
\hline & 100 & $0.00(0)$ & $0.32(18)$ & $0.17(10)$ & $1.30(73)$ & & & \\
\hline \multirow[t]{4}{*}{$15: 30 \mathrm{~h}, 51.7^{\circ}$} & 0 & $889.80\{23\}$ & $1156.53(30)$ & $1171.09(31)$ & $583.71(15)$ & 0.6 & 0.8 & 0.6 \\
\hline & 20 & $12.55(2)$ & $205.95(34)$ & $196.80(32)$ & $192.98(32)$ & & & \\
\hline & 80 & $0.00\{0\}$ & $2.74(26)$ & $1.43(14)$ & $6.22(60)$ & & & \\
\hline & 100 & $0.00(0)$ & $0.40(19)$ & $0.26(12)$ & $1.45(69)$ & & & \\
\hline
\end{tabular}

tral attenuation coefficients (Fig. 2 inset). Far-red light at $710 \mathrm{~nm}$ and green light at $565 \mathrm{~nm}$ penetrated deepest into the water under these conditions. There was an increase in the relative amount of far-red light at increasing depth within the bloom (Table 1). The contribution of far-red increased by 100 to $200 \%$ at depths of 20 to $100 \mathrm{~cm}$ within the water column as compared to the surface irradiance distribution. Absorption by water itself removed the last remaining photons at depths between 1 and $1.5 \mathrm{~m}$.

The increase in attenuation which occurred between 15 and 23 June 1994 was confirmed by Secchi disc measurements (Table 1) and by laboratory measurements of absorption and light scattering idata not shown). The reason for the increase was probably the intrusion of a more hypertrophic water mass from the inner area of the Darss-Zingst estuary, Germany. The shape of the spectral attenuation curve was similar on both days (Fig. 2 inset).

The observed changes in spectral composition of the underwater irradiance resulted in the relative amount of light energy available for absorption for PS1 becoming enriched in the lower half of the euphotic zone Such an imbalance in the excitation energy available to the photosystems is expected to cause state transition to occur To test whether the spectral irradiance conditions within the phytoplankton bloom affected energy distribution, samples from different depths were frozen in liquid nitrogen and the $77 \mathrm{~K}$ fluorescence emission spectra examined. Immediately frozen samples collected from the surface and at all depths in the early morning (Fig. 3A) showed a consistent 

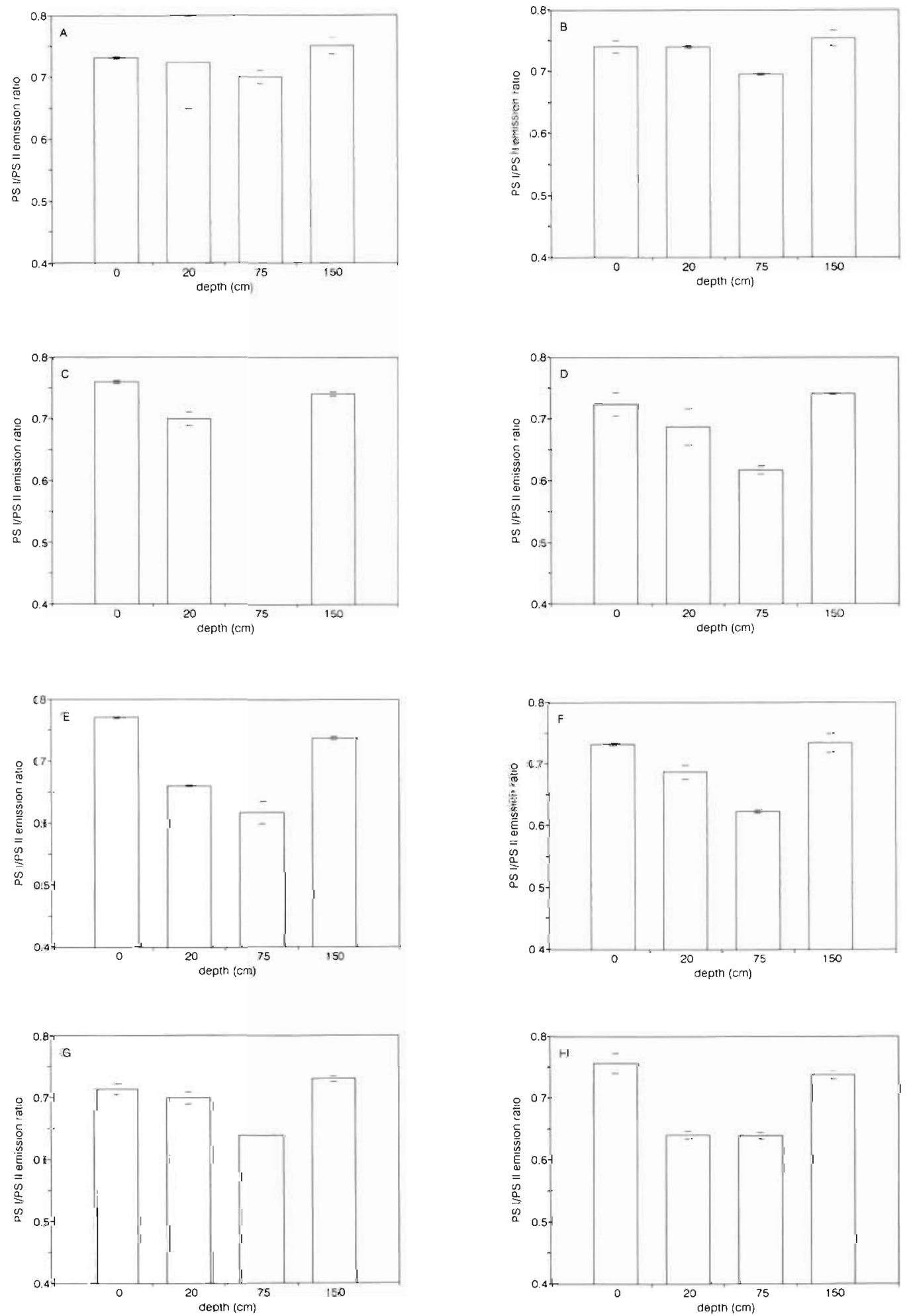

Fig. 3. Ratio of PS1 ( $717 \mathrm{~nm})$ to PS2 $(685 \mathrm{~nm}$ ) emission at $77 \mathrm{~K}$ for samples of natural phytoplankton. At time intervals during 14 June 1994, samples were either collected from different depths and frozen immediately [collected at (A) 07:45 h, (C) $09: 30 \mathrm{~h}$, (D) $12: 00 \mathrm{~h},(\mathrm{~F}) 14: 30 \mathrm{~h}$, (G) $17: 30 \mathrm{~h}$ ) or collected from $150 \mathrm{~cm}$, distributed into glass capillaries, and exposed to the irradiance in the water column for $10 \mathrm{~min}$ at depths of $0,20,75$, or $150 \mathrm{~cm}$ [incubated at (B) 07:45 $\mathrm{h}$, (E) $12: 00 \mathrm{~h}$, (H) $17: 30 \mathrm{hl}$ 
PS1/PS2 emission ratio of approximately 0.71. Samples were then collected from $150 \mathrm{~cm}$, distributed into pipettes, and exposed to the underwater irradiance at $0,20,75$ and $150 \mathrm{~cm}$ for a period of $10 \mathrm{~min}$. This treatment resulted in a decreased PS1/PS2 ratio for samples incubated at $75 \mathrm{~cm}$ (Fig. 3B). As surface irradiance increased throughout the morning, a depression of the PS1/PS2 ratio of samples collected and frozen immediately from 20 and $75 \mathrm{~cm}$ became increasingly apparent. Lowest ratios were always observed with samples from $75 \mathrm{~cm}$ (Fig. 3D, F, G) and are indicative of a transition to State 1. A high PS1/PS2 ratio indicative of State 2 was found in samples collected at the surface and from $150 \mathrm{~cm}$ deep. Ten minute incubations of $150 \mathrm{~cm}$ collected samples in situ at the different depths resulted in the same pattern of ratios, confirming that the differences observed were not due to stratification of the species composition throughout the water column (Fig. 3E, H). The range of PS1/PS2 values was greater after incubation than that observed in immediately collected samples. Occurrence of high PS1/PS2 ratios in darkness (at $1.5 \mathrm{~m}$ ) verified that the reduction of PS2 fluorescence due to the energy quenching (qE) component of non-photochemical quenching was not responsible for the fluorescence changes.

Additional exposures of $1.5 \mathrm{~m}$ collected phytoplankton samples to artificial light preferentially exciting PS1 or PS2 or to darkness resulted in a range of fluorescence emission ratios similar to those observed in the water column (Fig. 4). A minimum PS1/PS2 ratio of 0.62 was observed with narrow-band far-red incubation or with incubation at $75 \mathrm{~cm}$ in the water column. Maximum PS1/PS2 ratios of 0.75 to 0.76 were observed after exposure to $620 \mathrm{~nm}$ light or to 10 min darkness;

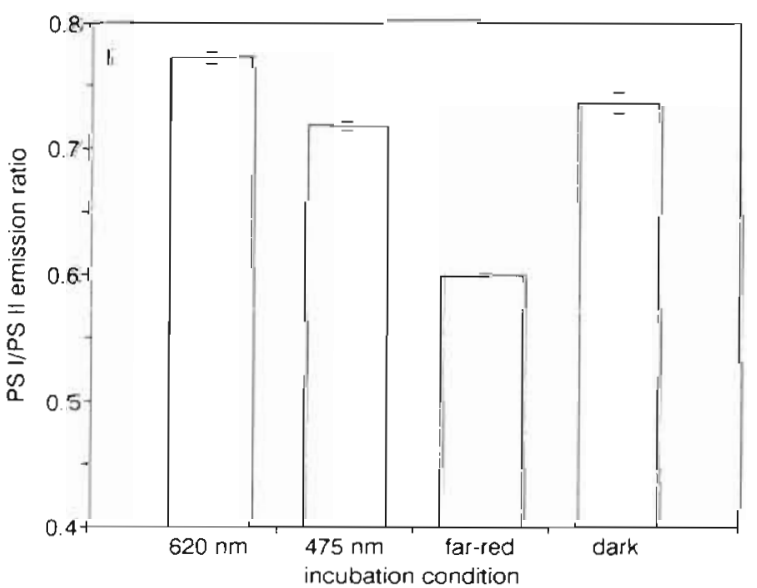

Fig. 4. Ratio of PS1 (717 nm) to PS2 (685 nm) emission at $77 \mathrm{~K}$ for samples of natural phytoplankton after 10 min exposures to artificial narrow-band light treatments or to darkness. Light at $620 \mathrm{~nm}$ selectively excited PS2 of cyanobacteria via PC. Irradiance at $475 \mathrm{~nm}$ selectively excited LHC of green algal PS2 via chl $b$. Far-red selectively excited PS1 in all cases highest field PS1/PS2 ratios were also caused by exposure to high surface irradiances, or by darkness (i.e. at $1.5 \mathrm{~m}$ ). The extremes of observed changes in low temperature fluorescence emission spectra for natural phytoplankton in State 1 and State 2 are shown in Fig. 5.

The same pattern of fluorescence responses was also observed throughout 23 June 1994, with cells in State 2 at the surface and at $1.5 \mathrm{~m}$, or in State 1 at $75 \mathrm{~cm}$. Underwater light measurements at Zingst and at other sites within the Darss-Zingst inlet throughout 1994 confirmed that the presence of high concentrations of phytoplankton and gelbstoff always resulted in a shallow euphotic zone characterised by an enhanced ratio of far-red light to photosynthetically active radiation (PAR). Light measurements at other sites in the Baltic Sea and southern North Sea with lower chlorophyll concentrations more typical of coastal waters did not show an increase in the relative amount of far-red (Forster \& Schubert unpubl.). Wavelengths above $700 \mathrm{~nm}$ are absorbed completely by $5.5 \mathrm{~m}$ of pure water (with $K_{710}=0.834 \mathrm{~m}^{-1}$; Smith \& Baker 1981), and therefore have an insignificant role in the ecology of phytoplankton from normal coastal waters.

Exposure of unialgal cultures of a green alga and a cyanobacterium to the prevailing underwater irradiance allowed a comparison to be made between the responses of phytoplanktonic organisms with different light-harvesting antenna systems. Ten minute incubations of the cyanobacterium Synechocystis 6803 in capillaries at different depths resulted in high PS1/PS2 ratios at the surface and at the bottom of the euphotic zone, whereas the lowest ratio was measured after exposure to the ambient irradiance at $75 \mathrm{~cm}$ (Fig. 6A).

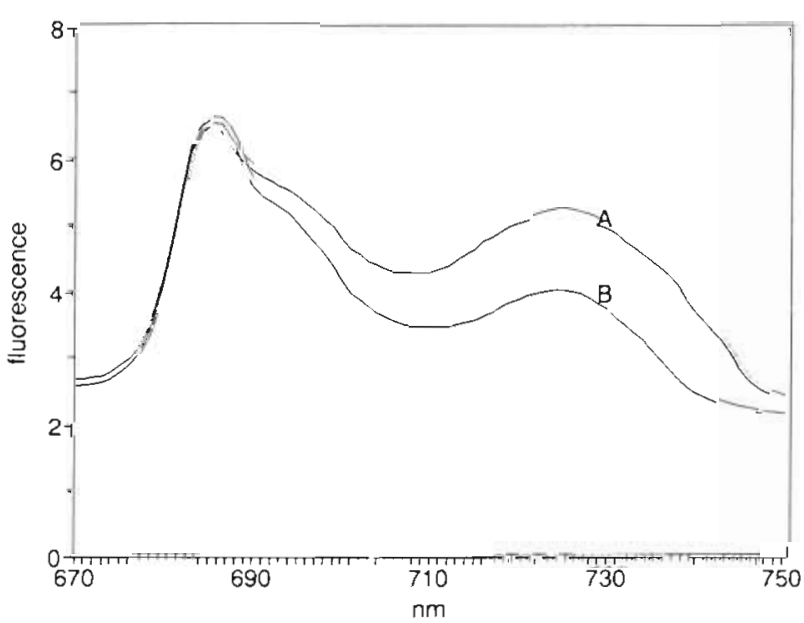

Fig. 5. Uncorrected $77 \mathrm{~K}$ fluorescence emission of fieldcollected samples from Zingst on 14 June 1994 at 12:00 h. Samples were frozen immediately after collection. (A) Surface sample, (B) $75 \mathrm{~cm}$ sample. Sharp peak at $685 \mathrm{~nm}$ due to PS2 emission, broader peak at $\sim 720 \mathrm{~nm}$ from PS1 


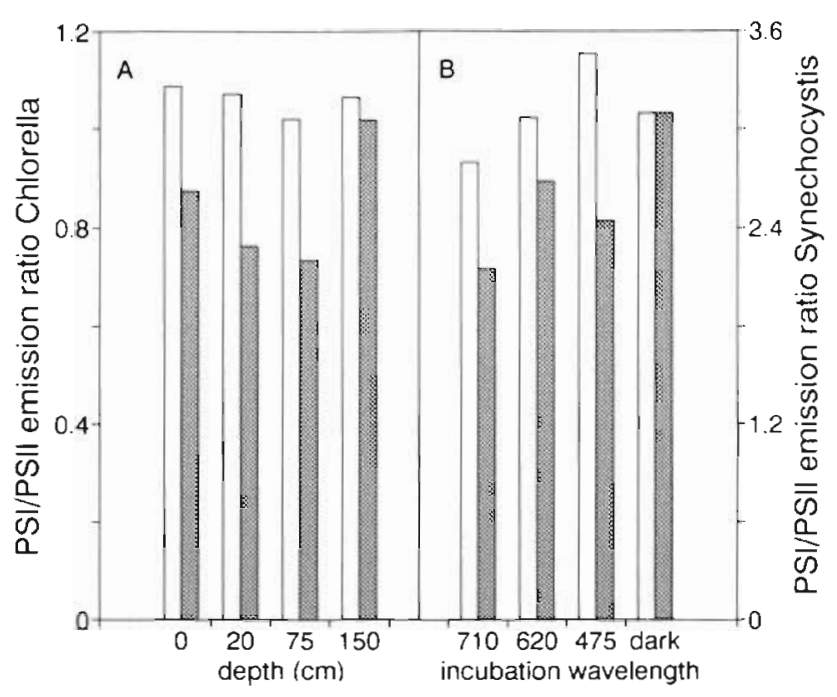

Fig. 6. PS1/PS2 emission ratios of a representative cyanobacterium (Synechocystis PCC 6803, shaded bars) and a green alga (Chlorella vulgaris, open bars). Algal suspensions were injected into glass pipettes and either $(A)$ incubated at different depths in the water column for $10 \mathrm{~min}$, or $(B)$ exposed to the artificial light sources described in Fig. 3

The natural variation in underwater irradiance was capable of driving maximal state transition in both directions in this organism, as shown by the comparison with artificial narrow-band irradiance conditions (Fig. 6B). For Chlorella vulgaris, the maximum range of PS1/PS2 ratios were not fully expressed after exposure to underwater irradiance conditions (Fig. 6A), but State 2 transition at the surface and at the bottom of the euphotic zone was noticeable.

Turbulent mixing within the phytoplankton bloom results in cells being exposed to rapid changes of both total and spectral irradiance, with equally rapid changes in the relative energy input to each photosystem. Successful equilibration of excitation energy by means of state transition requires a dynamic response from the algae on a time scale equal to or faster than the changes in irradiance (Cullen \& Lewis 1988). There are few published values for the rates at which state transition can occur; therefore, in order to relate the acclimation processes described above to natural time scales of mixing, it was necessary to measure the kinetics for state changes with samples of natural phytoplankton. Upon exposure of predarkened samples to monochromatic far-red, PS1/PS2 showed a large decrease within the first $4 \mathrm{~min}$, and reached a minimum value after $10 \mathrm{~min}$ exposure (Fig. 7). Removal of the samples to darkness at this point resulted in a reversion to State 2 , which was also complete within $10 \mathrm{~min}$. In the reverse treatment, full State 2 was reached within 4 min of exposure of predarkened samples to monochromatic $620 \mathrm{~nm}$ light.
Darkening of samples in State 2 resulted in a slight decrease of PS1/PS2 to the original starting value. Thus, the incubation time of $10 \mathrm{~min}$ used in our in situ experiments was sufficient to allow maximum state transition.

Corresponding kinetic analysis with unialgal cultures of a green alga and a cyanobacterium also showed rapid changes in fluorescence emission ratios, but with different kinetics between the species. Synechocystis PCC 6803 reached a maximum transition to State 1 within 2 min after FR exposure, and in the reverse test achieved full State 2 within $2 \mathrm{~min}$ of $620 \mathrm{~nm}$ exposure (Fig. 8A, C). A green alga typical of estuarine conditions, Scenedesmus quadriculata, responded to PS1 light and PS2 light more slowly, although the state change was still $80 \%$ complete within $5 \mathrm{~min}$ for both $\mathrm{FR}$ and $475 \mathrm{~nm}$ treatments (Fig. 8A, C). In both of these examples $440 \mathrm{~nm}$ excitation light was used when measuring emission spectra. Emission spectra measured with excitation light absorbed by the main light-harvesting pigments (590 nm or $475 \mathrm{~nm}$ for cyanobacteria or green algae respectively) resulted in the recording of a faster kinetic in the case of the cyanobacterium (Fig. 8B, D)

Estimations of the rate of wind-induced vertical mixing were made on several occasions representing different weather conditions throughout 1994 (Fig. 9). The diameter of Langmuir cells formed by wind-mixing was found to be equal to or deeper than the actual water depth when wind speeds were in excess of Force 3 (Beaufort scale), indicating that the whole water column of the Darss-Zingst inlet was subject to

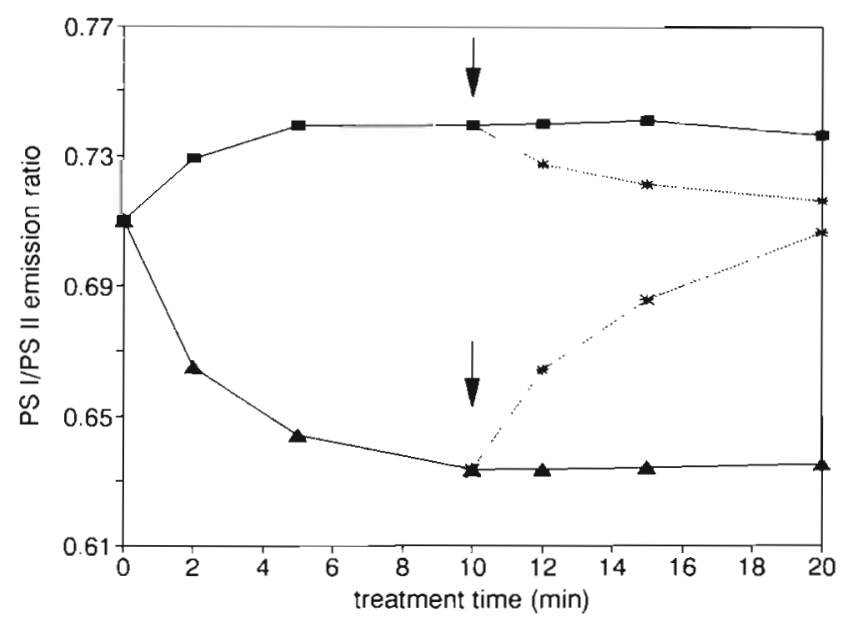

Fig. 7. Time course of state changes recorded with natural phytoplankton from Zingst. At time point 0 min, a sample of algae had been incubated in darkness for $20 \mathrm{~min}$. Samples were then distributed into pipettes and exposed to either farred (A) or to narrow-band irradiance at $620 \mathrm{~nm}(\mathbf{a})$. After 10 min, 3 pipettes from each treatment were removed and returned to darkness for the remaining $10 \mathrm{~min}(-\cdots-\cdots)$ 

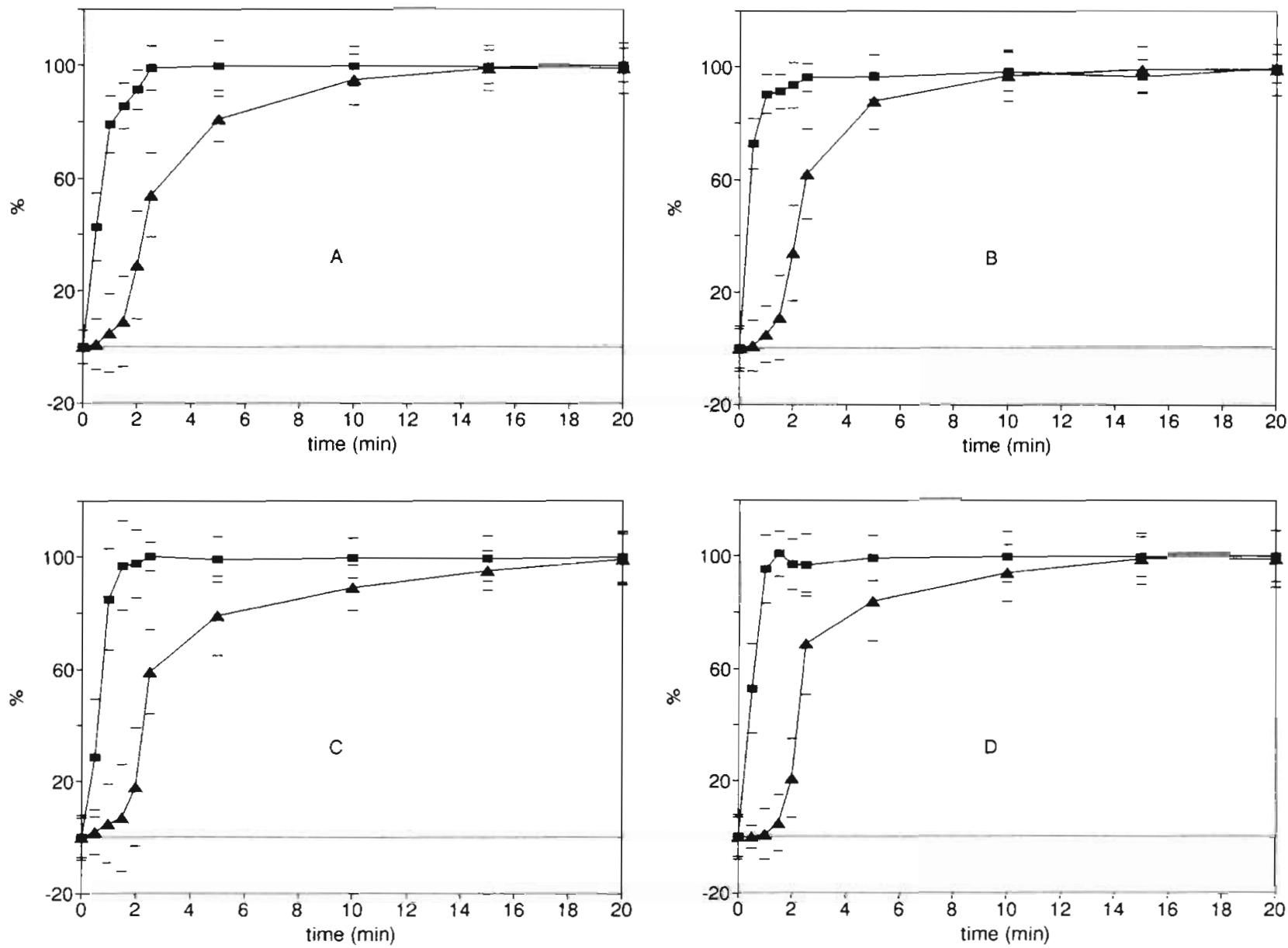

Fig. 8. Time course of state changes recorded with unialgal cultures of Synechococcus PCC 6803 (a) or Scenedesmus quadricauda ( $\wedge$ ). State transition is expressed as a percentage of the final PS1/PS2 value reached after exposure to the following irradiance conditions: (A, B) far-red incubation or (C, D) wavelength of peak absorption by PS2 antenna pigments, e.g. $475 \mathrm{or} 590 \mathrm{~nm}$ for green algae and cyanobacteria respectively. Excitation wavelength for monitoring of $77 \mathrm{~K}$ fluorescence emission was (A, $C)$ set to $440 \mathrm{~nm}$ or (B, D) set to excite the respective antenna pigments as described above. Pretreatment was 25 min darkness for all samples. Symbols represent mean $\pm \mathrm{SD}$

mixing. The time for 1 complete circulation of a Langmuir cell decreased from 23 min at Force 3 to 9 min at Force 6.

\section{DISCUSSION}

The light climate within dense phytoplankton blooms has not previously been reported in such detail. The spectral attenuation curve for diffuse underwater light measured with a spherical sensor resembled the absorption curve of a cyanobacterial culture for wavelengths between 500 and $700 \mathrm{~nm}$. Strong attenuation by DOM and phytoplankton pigments resulted in an enhanced contribution of far-red light to total irradiance with increasing depth. The remaining visible light was concentrated at wavelengths $(-565 \mathrm{~nm})$ at which photosynthetic pigments of the algal community absorbed poorly. This resulted in an imbalance in energy input to the 2 photosystems of the algae: PS1, which contained long-wavelength absorbing forms of chl $a$, received a greater energy input than PS2. As expected under these conditions, a redistribution of excitation energy was observed. Exposure to the farred enriched light present throughout most of the euphotic zone caused a conversion to State 1 , as shown by low temperature emission spectra of the phytoplankton. It is thought that oxidation of intersystem electron carriers by PS1 is responsible for State 1 formation, with the signal possibly being transduced to the light-harvesting apparatus by means of a redoxsensitive protein kinase (Allen 1992). Dark treatment has previously been shown to cause formation of State 2 in cyanobacteria (Dominy \& Williams 1987) and, to a lesser extent, in green algae (Satoh \& Fork 1983, Turpin \& Bruce 1990), thus explaining the occur- 


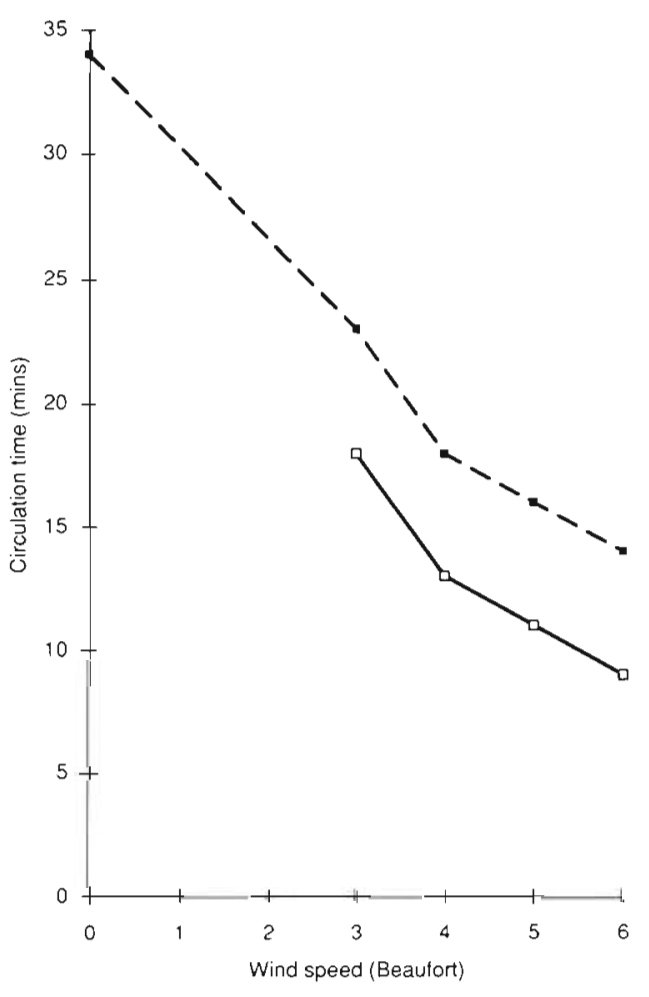

Fig. 9. Reduction in circulation time of Langmuir cells with increasing wind speed for 2 stations in the Darss-Zingst estuary. (- - Z) Zingst, ( - ) Dierhagen, at the western end of the estuary. Measurements took place throughout November 1994

rence of State 2 observed in samples from the bottom of the euphotic zone. In this case, reduction of the thylakoid plastoquinone pool by input of electrons from respiratory chain components is thought to be responsible for dark formation of State 2. Exposure to high irradiance at the surface also results in reduction of all electron carriers due to substrate limitation at the acceptor side of PS1.

The natural variation in spectral irradiance in the water column was capable of causing the maximum range of State 1 and State 2 formation for samples of the natural cyanobacterial bloom. Unialgal cultures of Synechocystis PCC 6803 responded similarly, but did not achieve full expression of State 2 after exposure to full surface irradiance. The difference in response may be due to the higher $\mathrm{CO}_{2} / \mathrm{HCO}_{3}{ }^{-}$content of the culture medium than of the seawater, which allowed higher rates of electron flow under light-saturating conditions, thus giving a more oxidised plastoquinone pool. Alternatively, greater absorption of sunlight by the antenna of PS2 than that of PS1 may have caused a larger state transition for the natural phytoplankton. Emission of Chlorella vulgaris cultures at $77 \mathrm{~K}$ was less strongly affected by exposure to the natural variations in underwater irradiance. Dark treatment did not induce State 2 , indicating low chlororespiratory activity in this species

The time required for state transition to occur was found to be similar to or less than the circulation time for Langmuir cells in the water column (for wind speeds up to Force 6). Comparative studies of a coccoid cyanobacterium and a green alga demonstrated that the cyanobacteria was able to respond faster to changes in spectral irradiance. If this is a general feature of cyanobacteria, then some selective advantage may be obtained during periods of intense mixing. As the Darss-Zingst estuary has a mean depth of only $2 \mathrm{~m}$, the whole water column is subject to wind-induced mixing on most days. The mixing results in exposure of phytoplankton cells to a rapidly changing light climate. Short-term acclimation of the photosynthetic apparatus to the irradiance conditions would be advantageous if photooxidative damage during light-saturating conditions could be minimised, or if efficiency of light utilisation could be increased under light-limiting conditions. Transition to State 2 on exposure to high surface irradiance serves to reduce the excitation energy input to PS2 and may reduce the danger of photodamage to reaction centre proteins (McTavish 1988). State 1 formation at depths where light is limiting balances the distribution of energy between the photosystems and may increase the efficiency of linear electron transport. Cyanobacteria in State 1 have more efficient energy transfer from PBS to PS2, due to tighter coupling at the molecular level (Mullineaux \& Allen 1988).

State transition of the natural cyanobacteria-dominated phytoplankton community was however not as fast as the unialgal Synechocystis culture, perhaps due to the natural phytoplankton being acclimated to and tested at a lower temperature (Dominy \& Williams 1987 ) or being in a poorer physiological condition. In addition, the natural phytoplankton community also contained green algae, which showed less reaction to the changes in underwater irradiance (c.f. Chlorella results). The more extreme PS1/PS2 values recorded for natural phytoplankton after $10 \mathrm{~min}$ incubation as compared to immediately collected samples, particularly at the surface and at $20 \mathrm{~cm}$, indicate that mixing near the surface (where the light gradient is steepest) is slightly faster than the time required for full state transition to occur.

State transition can thus be added to the list of other physiological acclimation mechanisms such as $\mathrm{pH}$ dependent (Krause \& Weis 1991) or xanthophyll cycledependent (Olaizola \& Yamamoto 1994, Schubert et al. 1994) energy dissipation mechanisms which phytoplankton use to regulate photosynthesis in response to fluctuating irradiance. In contrast to higher plants and green algae (Falkowski \& Fujita 1987), in which state 
transition is thought of as a minor regulatory mechanism, the situation in cyanobacteria may be quite different. Differences in stoichiometry of the photosystems and large differences in absorption cross-section of the photosystems, combined with absence of the xanthophyll cycle, suggest that state transition may be of greater importance as a regulatory mechanism in cyanobacterial photosynthesis (Büchel \& Wilhelm 1993), particularly under bloom conditions or in benthic mats.

Acknowledgements. This work was funded by research grant 03 F $0120 \mathrm{~B}$ of the German Federal Ministry for Training and Research. The authors thank Mr Peter Feuerpfeil for skilful technical assistance.

\section{LITERATURE CITED}

Allen JF (1992) Protein phosphorylation in regulation of photosynthesis. Biochim Biophys Acta 1098:275-335

Biggins J, Bruce D (1989) Regulation of excitation energy transfer in organisms containing phycobilins. Photosynth Res 20:1-34

Bonaventura C, Myers J (1969) Fluorescence and oxygen evolution from Chlorella pyrenoidosa. Biochim Biophys Acta 189:366-383

Bruce D, Biggins J, Steiner T, Thewalt M (1985) Mechanism of the state transition in photosynthesis. IV. Picosecond fluorescence spectroscopy of Anacystis nidulans and Porphyridium cruentum in state 1 and state 2 at $77 \mathrm{~K}$. Biochim Biophys Acta 806:237-246

Büchel C, Wilhelm C (1993) In vivo analysis of slow chlorophyll fluorescence induction kinetics in algae: problems and perspective. Photochem Photobiol 58:137-148

Butler WL (1978) Energy distribution in the photochemical apparatus of photosynthesis. A Rev Plant Physiol 29:345-378

Canaani O, Barber J, Malkin S (1984) Evidence that phosphorylation and dephosphorylation in vivo are the mechanism for regulation of distribution of excitation energy - photoacoustic and fluorometric study of an intact leaf. Proc Natl Acad Sci USA 766:513-524

Cullen JJ, Lewis MR (1988) The kinetics of algal photoadaptation in the context of vertical mixing. J Plankton Res 10: $1039-1063$

Dominy PJ, Williams WP (1987) The role of respiratory electron flow in the control of excitation energy distribution in blue-green algae. Biochim Biophys Acta 892:264-274

Falkowski P, Fujita Y (1987) Effects of light state transitions on the apparent absorption cross section of photosystem II in Chlorella. In: Biggins J (ed) Progress in photosynthesis research, Vol IV. Martinus Nijhoff, Dordrecht, $p$ $737-740$

Falkowski PG, Greene R, Kolber Z (1994) Light utilisation and photoinhibition of photosynthesis in marine phytoplankton. In: Baker NR, Bowyer JR (eds) Photoinhibition of photosynthesis - from molecular mechanisms to the field. BIOS, Oxford, p 407-432

Falkowski PG, LaRoche J (1991) Acclimation to spectral irradiance in algae. J Phycol 27:8-14

Fork DC, Satoh K (1986) The control by state transitions of the distribution of excitation energy in photosynthesis. A Rev Plant Physiol 37:335-361
Fujita Y, Ohki K, Murakami A (1985) Chromatic regulation of photosystem composition in the photosynthetic system of red and blue-green algae. Plant Cell Physiol 26: $1541-1548$

Horton P (1989) Interaction between electron transport and carbon assimilation: regulation of light harvesting and photochemistry. In: Briggs WR (ed) Photosynthesis. Alan R Liss, New York, p 393-406

Horton P, Allen JF, Black MT, Bennett J (1981) Regulation of phosphorylation of chloroplast membrane polypeptides by the redox state of plastoquinone. FEBS Lett 125:193-196

Kirk JTO (1994) Light and photosynthesis in aquatic ecosystems. Cambridge University Press, Cambridge

Krause GH, Weis E (1991) Chlorophyll fluorescence and photosynthesis: the basics. A Rev Plant Physiol Plant Mol Biol 42:313-349

McTavish H (1988) A demonstration of photosynthetic state transitions in nature. Photosynth Res 17:247-254

Mohanty N, Bruce D. Turpin DH (1991) Dark ammonium assimilation reduces the plastoquinone pool of photosystem II in the green alga Selenastrum minutum. Plant Physiol 96:513-517

Mullineaux CW (1992) Excitation energy transfer from phycobilisomes to Photosystem 1 in a cyanobacterium. Biochim Biophys Acta 1100:285-292

Mullineaux CW, Allen JF (1988) Fluorescence induction transients indicate dissociation of photosystem Il from the phycobilisome during the state-2 transition in the cyanobacterium Synechococcus 630. Biochim Biophys Acta 934: $96-107$

Murata N (1969) Control of excitation transfer in photosynthesis. I. Light-induced change of chlorophyll a fluorescence in Porphyrudium cruentum. Biochım Biophys Acta 172:242-251

Olaizola M, Yamamoto HY (1994) Short-term responses of the diadinoxanthin cycle and fluorescence yield to high irradiance in Chaetoceros mueller (Bacillariophyceae). J Phycol 30:606-612

Rippka R, Deruelles J, Waterburg JB, Herdman M, Stainier RY (1979) Genetic assignments, strain histories and properties of pure cultures of cyanobacteria. J gen Microbiol 111:1-61

Satoh K, Fork DC (1983) The relationship between state Il to state I transitions and cyclic electron flow around PS1. Photosyn Res 4:245-256

Schubert H, Kroon BMA, Matthijs HCP (1994) In vivo manipulation of the xanthophyll cycle and the role of zeaxanthin in the protection against photodamage in the green alga Chlorella pyrenoidosa. J biol Chem 269:1-6

Smith RC (1968) The optical characterisation of natural waters by means of an extinction coefficient. Limnol Oceanogr $13: 423-429$

Smith RC, Baker K (1981) Optical properties of the clearest natural waters. Appl Optics 20:177-184

Turpin DH, Bruce D (1990) Regulation of photosynthetic light harvesting by nitrogen assimilation in the green alga Selenastrum minutum. FEBS Lett 263:99-103

Veeranjaneyulu K, Leblanc RM (1994) Action spectra of photosystems $I$ and II in state 1 and state 2 in intact sugar maple leaves. Plant Physiol 104:1209-1214

Williams WP, Allen JF (1987) State 1/state 2 changes in higher plants and algae. Photosynth Res 13:19-45

Wollman FA, Bulte L (1989) Towards an understanding of the physiological role of state transitions. In: Hall DO Grassi $G$ (eds) Photosynthetic processes tor energy and chemicals. Elsevier Publishers, London, p 198-207

Manuscript first received: February 27, 1995

Revised version accepted: June 8, 1995 